\title{
VIEJAS Y NUEVAS INTERSECCIONES ENTRE RELIGIÓN E IDENTIDAD: HACIA UN MARCO ANALÍTICO
}

\author{
Old and new intersections between religion and identity: toward an \\ analytical frame \\ Alfonso Pérez-Agote*; Jose Santiago* \\ * GRESCO-TRANSOC, Universidad Complutense de Madrid \\ pereza@cps.ucm.es; jasantiago@cps.ucm.es
}

La identidad y la religión son aspectos de la vida individual y de la vida social cuyo estudio por parte del científico social aleja a éste hacia las antípodas del quehacer de los científicos de la naturaleza. Los científicos sociales no podemos aspirar a saber qué es la religión o la identidad. Porque tanto la primera como la segunda pertenecen a la esfera de la conciencia de los seres humanos $y$, por lo tanto, su existencia no depende de su veracidad. No es ni posible ni siquiera interesante para el científico social saber si la religión católica es verdadera o si la idea que tienen los individuos de sí mismos o de lo que llaman su nación lo es. Estas ideas están dentro de lo que llamamos representaciones, individuales o sociales. De aquí proviene la diferencia substantiva entre la fenomenología de los filósofos, de Husserl, y la fenomenología que hacemos los sociólogos, la fenomenología social. Los sociólogos sabemos de la inutilidad sociológica, por supuesto- de la pasión de los filósofos husserlianos por mostrar cómo la reducción fenomenológica no sólo constituye la representación en objeto sino que alcanza el objeto de la representación. A los sociólogos nos es suficiente con hacer de la representación nuestro objeto de análisis, sin preguntarnos por la veracidad de la representación: no nos interesa si las definiciones de una religión son verdaderas, ni si las ideas sobre quiénes o cómo somos lo son. Nos interesan, por un lado, el proceso de constitución y de aceptación social de esas creencias, el éxito social que alcanzan y los mecanismos sociales que producen ese éxito; $y$, 
por otro, las determinaciones del comportamiento que llevan a cabo esas creencias en quienes las mantienen.

Claro está que también para los sociólogos es importante la cuestión de saber si nuestras conclusiones de investigación son verdaderas o falsas, si se acercan más que otras a lo que está ocurriendo en la sociedad. Pero nuestra función central y directa no es saber si lo que piensan o creen los individuos es verdadero o falso, sino, más bien, cómo llegan al éxito social las definiciones de la realidad y en qué manera y dirección determinan el comportamiento de los individuos.

La identidad está inscrita tanto en la vida individual como en la social. Cada individuo y cada grupo fabrican su propia historia. La historia de cualquier grupo está fabricada y mantenida por sus miembros, e, incluso, dentro de algunos grupos, se divide el trabajo y algunos miembros se especializan para fabricarla; y, por otra parte, además puede ser contada por historiadores que no pertenecen al grupo. La historia de un individuo se la cuenta él mismo, seleccionando, con importantes dosis de arbitrariedad, los hechos significativos. Los neurólogos son los que más saben de cómo cambian de lugar los recuerdos en la compleja estructura de nuestro cerebro. Y el psiquiatra y, sobre todo el psicoanalista, nos pueden ayudar a construirnos una memoria más aceptable de nosotros mismos.

La historia de los historiadores es una ciencia especial en el ámbito de las relaciones entre la ciencia y la realidad; es la cuestión de la verdad. La historia supone una relación diferente y directa con la realidad. Contiene en sí una paradoja fuerte, por no decir una fuerte contradicción. Foucault nos lo advierte, sirviéndose de las ideas de Nietzsche: contrapone lo que llama la historia efectiva a la historia de los historiadores. La historia será efectiva en la medida en que introduzca lo discontinuo en nuestro mismo ser. Mientras que los historiadores, al hacer la historia de lo que no es sino un producto histórico, proyectan la actual realidad, la actual unidad, al principio, a los orígenes. Pero lo que se encuentra en el comienzo histórico de las cosas no es la identidad de lo que hoy día conocemos, sino, más bien, es el desorden de las otras cosas, el disparate. Foucault nos recuerda que para Nietzsche el conocimiento no tiene otro objetivo que la destrucción de nuestras certidumbres. Para este, la historia de los historiadores sería siempre historia sagrada, pues sería la consagración de la idea de que el ser de hoy existía ya en el origen (Foucault, 1971). Contar la historia de un grupo contemporáneo supondría así: a) predicar la existencia de ese grupo en el origen, bajo la apariencia de contar cómo ese grupo se ha ido 
formando; b) dotar a ese origen de una existencia segura, no cuestionable, mitificándolo (mito fundacional o de los origenes); y c) dotar a esta incuestionabilidad de una base culturalmente suficiente; las formas más duras y eficientes de esta incuestionabilidad han sido, históricamente, la religiosa (pueblo elegido en culturas eminentemente religiosas) y la biológica (raza en culturas en las que lo biológico es sinónimo de lo dado). Claro está, también, que los buenos historiadores son los que nos transmiten la idea clara de que el producto histórico sobre el que escriben su historia pudo no haberse producido, haciéndonos comprender los mecanismos que lo han hecho posible.

Durkheim dedica Las formas elementales de la vida religiosa (1968) a mostrarnos cómo el grupo, visto desde la exterioridad del sociólogo, está atravesado por la arbitrariedad originaria: pudo perfectamente no haber sido, lo que significa que en el futuro puede no ser. Sacralizar la existencia del grupo significa conjurar la arbitrariedad originaria, protegiendo con interdictos la manipulación de lo consagrado: no se podrá manipular, ni siquiera mentalmente (metafóricamente hablando), aquello que simboliza el grupo sin llevar a cabo las formas rituales necesarias que están controladas por la autoridad grupal correspondiente. Erikson (1960) habla

"Decimos que es el mismo Estado, el mismo ejército, la misma asociación que existe hoy y el o la que existía ya hace decenas y puede ser que centenas de años; sin embargo, entre los miembros actuales del grupo no hay uno solo que sea el mismo que antaño". (Simmel, 1896-97: 75) de la identidad como un sentimiento subjetivo y tónico de una unidad personal (sameness, mismidad) y de una continuidad personal en el tiempo. Este sentimiento no puede tener otro soporte que el individuo. Pero, por otra parte, el individuo se siente perteneciente a ciertos grupos y no perteneciente a otros. Ese sentimiento

de mismidad y continuidad es el registro último de la identidad personal que nos hace únicos. El otro nivel de la identidad personal es el de la identidad colectiva, que consiste en la diversidad de pertenencias grupales del individuo y marca la conciencia de pertenencia a esos grupos. La conciencia sólo existe en el individuo, pero el grupo es una realidad supraindividual. No solamente lo corpóreo es real ${ }^{1}$. El grupo es real;

\footnotetext{
${ }^{1}$ El término real tiene dos acepciones diferentes: la que se opone a inmaterial y la que se opone a lo irreal, a lo inexistente. Para los sociólogos, el grupo es una realidad inmaterial que, claro está, solamente puede existir a partir de los cuerpos de los individuos que lo forman.
} 
necesita de los individuos para existir, pero su realidad supera la suma de sus individuos. Como sociólogos, podemos ir más allá de la pura conciencia individual y enfocar el proceso de creación y mantenimiento de los grupos, de esas interrelaciones grupales de los individuos. Como sociólogos sabemos de la desigualdad social existente en relación a la capacidad de generar la definición de una identidad colectiva, atribuyendo significación social a algún rasgo diferencial; y también de la desigualdad a la hora de difundir esa significación. Se trata de un proceso de creación, difusión y, por último, de aceptación generalizada (éxito social) de la significación dentro del conjunto de los que lo poseen. El rasgo seleccionado puede ser biológico o social, pero la significación es siempre social. Ningún rasgo produce per se una significación universal: el color de la piel puede llegar a ser socialmente significativo si sobre un espacio conviven individuos de distinto color de piel; a partir de esa diferencia puede darse un proceso de creación y difusión de significación. Ningún rasgo produce por su sola existencia una significación determinada.

Lo que necesita la definición grupal para tener éxito no es una estructura de plausibilidad lógica o científica sino una estructura de plausibilidad social, es decir, un medio social en el que esta definición tenga sentido para los actores, lo que depende de las percepciones que tengan estos del rasgo objetivo más que del rasgo mismo. En muchos casos en que se generan movimientos en defensa de una pretendida (cierta o no) identidad cultural, nos encontramos con que son coyunturas críticas en que los rasgos diferenciadores pretendidamente objetivos han poco menos que desaparecido, pero su proceso de desaparición ha sido vivido traumáticamente, lo que constituye un buen caldo de cultivo, una estructura de plausibilidad social, para una definición en términos de identidad basada en rasgos pretendidamente objetivos. Las definiciones sociales de la identidad son de tipo esencialista, pues su discurso se conforma en términos de los rasgos objetivos que constituirían la esencia del colectivo y presentan a la propia conciencia de identidad como emanación o producto de esos rasgos objetivos.

Tajfel (1984: 264) enumera los componentes que con mayor o menor intensidad constituyen lo que es un grupo de pertenencia: "componente cognitivo, en el sentido del conocimiento de que uno pertenece a un grupo; componente evaluativo, en el sentido de que la noción de grupo y/o de la pertenencia de uno a él puede tener una connotación valorativa positiva o negativa; y componente emocional, en el sentido de que los 
aspectos cognitivo y evaluativo del grupo y de la propia pertenencia a él pueden ir acompañados de emociones (tales como amor u odio, agrado o desagrado) hacia el propio grupo o hacia grupos que mantienen relaciones con él".

\section{P.: Además del Credo y los Artículos, ¿creéis otras cosas? \\ R.: Sí, Padre, todo lo que está en la Sagrada Escritura y cuanto Dios tiene revelado a su Iglesia. \\ P.: ¿Qué cosas son ésas? \\ $R$ : Eso no me lo preguntéis a mí que soy ignorante; doctores tiene la santa Madre Iglesia que lo sabrán responder}

Este catecismo del jesuita Gaspar Astete, publicado en el siglo XVI, fue muy utilizado por la Contrarreforma, tras el Concilio de Trento, tanto en España como en América Latina. Su utilización para la formación religiosa ha durado siglos. Está compuesto en forma de preguntas de la autoridad católica a quien quiere ser buen cristiano y de las respuestas que éste, para serlo, debe dar. En este texto citado se pueden apreciar varias cosas: la división del trabajo en relación con el conocimiento de la verdad religiosa, la no manipulación de la verdad religiosa por los fieles e, incluso, el elogio de la ignorancia.

El contenido cognitivo de un grupo varía de unos grupos a otros. Hay grupos como los religiosos que pueden tener un componente cognitivo muy fuerte. En otros, este componente se puede reducir hasta el mínimo, lo que corresponde al hecho de conocer que se es miembro del grupo. Dentro del mismo tipo, por ejemplo el tipo religioso, se pueden dar grupos que tengan mayor componente cognitivo que otros, como puede ocurrir en relación al grado de elaboración doctrinal y también al grado de conocimiento de la propia doctrina por los miembros. Y también pueden darse diferencias de conocimiento entre los miembros del mismo grupo, pudiéndose llegar, incluso, a la especialización en la posesión, el desarrollo y el control del conocimiento por parte de ciertos miembros o ciertos subgrupos. Pensemos, dentro de un grupo religioso, en sacerdotes, teólogos, dignatarios, simples fieles: toda una división social del trabajo y del poder.

La conciencia de identidad colectiva se percibe a sí misma por sus miembros como la emanación de rasgos objetivos, pero esta significación no es una emanación necesaria de un rasgo sino el resultado de un proceso social de creación, difusión y aceptación de una significación determinada, que es lo que estudiamos los sociólogos.

Lo que separa un agregado estadístico (conjunto de individuos que tienen una característica común) de un agregado social o grupo (conjunto de individuos que tienen sentimiento de pertenencia a un todo, basado generalmente en la pretensión de posesión de un rasgo común) es una 
arbitrariedad lógica o teórica. No hay razón lógica o teórica para que se forme un grupo (conciencia de pertenencia) y, por tanto, no es predecible su formación a partir de la mera existencia de ese rasgo. Un grupo se funda como relación arbitraria de inclusión-exclusión. Los actores, miembros del grupo, no pueden pensar, sin embargo, en términos de arbitrariedad lógica, produciendo un discurso racionalizador sobre la existencia del grupo y protegiendo con interdictos aquella arbitrariedad, sacralizándola o naturalizándola.

En nuestros días se procura esta seguridad al predicar del atributo fundador de nuestra identidad un carácter de fijeza, de objetividad que lo sitúe simbólicamente más allá de toda duda: por eso es frecuente la tendencia a la naturalización (biologización) de los colectivos, o a la objetivación cultural (el patrimonio cultural adquiere un sentido político importante como objetivador de una identidad cultural). Esta es la tesis fundamental mantenida por Durkheim en Las formas elementales de la vida religiosa (1968): sacralizar el fundamento del grupo equivale a hacer que este fundamento no pueda ser manipulado ni física ni mentalmente, pues se sitúa más allá, fuera de nuestro alcance, a través de toda una serie de prohibiciones

Durkheim se ocupa de analizar cómo se construyen socialmente las certidumbres que permiten a los miembros del grupo pensar y sentir que éste tiene una razón de ser. Nietzsche, en cambio, se preocupa por destruir esas mismas certidumbres: el saber debe destruir nuestras certidumbres, introducir lo discontinuo en nuestro mismo ser; lo que, en el fondo, no es sino la piadosa resolución de quien cree, aquí está su propia certidumbre, que se puede vivir sin alguna. Hacer como si es condición humana necesaria para la acción.

Pero no se tata de una arbitrariedad social, sino que la formación de grupos, de definiciones de la realidad social grupal, evidentes para los miembros o políticamente objetivadas, es producto de un proceso histórico-social. La arbitrariedad, sin embargo, es relativa, porque para que la definición arbitraria tenga éxito social necesita una plausibilidad social, es decir, un medio social en el que la definición tenga sentido para los actores, lo que depende de las percepciones que estos tengan del rasgo más que del rasgo mismo.

Este tipo de realidades, las realidades sociales, es muy particular: cuando los individuos definen una realidad colectiva, si tienen éxito social, generan 
la realidad definida. Este proceso es el de constitución de cualquier grupo humano o conjunto de personas que tienen conciencia de pertenencia común, con o sin interacción entre ellos. Recordemos aquí, en el campo de estas realidades sociales, el interesante texto de Merton (1980) sobre el caso de las profecías falsas que se autocumplen por el mero hecho de ser enunciadas; o el de las verdaderas que fracasan por haberlo sido; o el de falsas que siguen siendo verdaderas para un grupo determinado bajo la condición de romper la comunicación con el resto de la sociedad y convertirse en autorreferente (Pérez-Agote, 2008: 276-285).

Existen varias formas de objetivación social de una definición grupal: el mutuo reconocimiento por parte de los actores que se autodefinen como grupo, el reconocimiento del grupo por los otros y la objetivación política administrativa, que puede llevar incorporada la fuerza, la coacción. Las relaciones entre estas formas de objetivación con respecto a un agregado concreto, pueden ser de coincidencia o de no coincidencia. Entendemos por objetivación de la identidad colectiva o del grupo el grado de independencia que alcanza su existencia con respecto a la voluntad de los individuos integrantes. Dada la posibilidad performativa de producción por los actores de una identidad colectiva, el grado de objetivación más débil es el meramente fundacional, es decir, el mutuo reconocimiento entre sus miembros. Coincide así con la existencia misma del grupo, que alcanza así el mínimo grado de independencia. El segundo grado sería el reconocimiento por los otros, siendo el conflicto entre grupos una de las formas posibles de reconocimiento. Mención especial debe hacerse sobre el hecho de que la coincidencia de ambos grados puede llevar aparejada una evidencia social en torno a la existencia del grupo, lo que implica una eficacia simbólica muy fuerte. El tercer nivel es la objetivación políticoadministrativa que implica una sanción política de la existencia del grupo. La coincidencia de las tres formas sobre un grupo indica existencia del grupo, ausencia de puesta social en tela de juicio y reconocimiento político oficial. Pero pueden darse formas de no coincidencia. Si se da el primer nivel, mutuo reconocimiento, sin que se de el segundo, reconocimiento por los otros, estamos ante un caso de falta de reconocimiento social; o de falta de conocimiento, como es el caso de los grupos clandestinos, las sociedades secretas, etc. Podemos pensar también en una situación en la que se dé el segundo nivel sin que se dé el primero. El renegado o el que abandonó un grupo puede seguir siendo considerado miembro por los demás en contra de su propia voluntad; San Pedro, por ejemplo, negó 
formar parte de los del Galileo, pero la gente le reconocía como uno de sus seguidores por su acento. También puede darse una falta de correspondencia entre el primer y el tercer nivel. Es el caso de los nacionalismos étnicos y periféricos en relación al Estado unitario.

La consecuencia metodológica directa del planteamiento en términos de arbitrariedad lógica y determinación social de las que hemos llamado realidades colectivas es la necesaria consideración en nuestra investigación empírica de dos momentos metodológicos fundamentales, el fenomenológico y el genético, ambos ineludibles.

Si la eficacia social, en el sentido expresado de determinación del comportamiento, de una idea no depende en particular de su mayor o menor veracidad, sino de la capacidad que se tenga para imponerla como verdadera a través de mecanismos sociales, entonces: 1) el momento fenomenológico garantiza la inexistencia de juicio de cientificidad sobre las imágenes o creencias sociales que toma como objeto de análisis, juicio que sería tan de valor como el basado en la moralidad, la justicia o la conveniencia política; 2) el momento genético garantiza, por el contrario, el alejamiento de una posición idealista, al considerar las imágenes, creencias, etc. como variables dependientes, acercándonos a sus determinaciones objetivas y a los mecanismos sociales que operan su producción y reproducción. La consideración de ambos momentos es necesaria, pues, en un extremo, ignorar los fetiches y las ilusiones de una época es ignorar aquello que mueve a los seres humanos, y, en el otro extremo, reconocerlos como realidad única, sería reconocer que no hay mejor sociología que el sentido común, en el sentido más estadístico que podamos otorgar a la expresión.

La sociología nació como ciencia de la modernidad de los países europeos occidentales y en la idea general de la modernidad se concebía que con la modernización, con la nueva racionalidad, la religión iría perdiendo importancia en estas sociedades e, incluso, desapareciendo. Históricamente la unificación política de esos países les había ido llevando generalmente -a partir del principio cuius regio eius religio aplicado a partir de la Paz de Westfalia- a su homogeneización religiosa. El proceso de génesis de los Estados Unidos fue un caso muy especial pues se trataba de un pais formado por fuertes flujos de inmigrantes; su proceso de modernización no llevó consigo una secularización tan fuerte de la población y, así, fue considerado como la primera excepción a la teoría de la secularización, parte fundamental de la de la modernización. Después 
vinieron a considerarse otras excepciones, las de sociedades en las que el proceso de desarrollo tampoco fue induciendo un proceso tan fuerte de secularización como en aquellas sociedades europeas. Todo ello ha llevado a la idea de que, en realidad, son aquellos primeros países europeos la verdadera excepción.

Cuando ya los sociólogos habíamos ido aceptando la excepcionalidad europea, resulta que la nueva pluralidad religiosa, producida por la llegada de poblaciones de las viejas colonias europeas a partir del final de la Primera y, sobre todo, de la Segunda Guerra Mundial, ha venido a colocar la religión en el centro de nuestra atención, por lo que implica de proceso inverso al de la homogeneización y al de secularización de aquellos viejos países europeos. La primera generación de estas poblaciones inmigradas llega, tras las dos Guerras Mundiales, en momentos en que en Europa se necesitaba nueva mano de obra. El mercado de trabajo fue así el gran mecanismo que posibilitó su inserción. Con la mentalidad pragmática propia de quien ha sacrificado gran parte de sus afectos al abandonar el territorio originario, esta primera generación facilitó a sus hijos, segunda generación, la entrada en las instituciones públicas educativas de la sociedad a la que llegó. Los diferentes modelos de integración social, el de la asimilación cultural, propio de Francia, o el de la permisividad de las culturas étnicas en el ámbito privado de la vida, propio del Reino Unido, mostraron con el tiempo su fracaso. Todo empieza cuando los miembros de la segunda generación, a la salida del sistema educativo, comienzan a tener problemas para encontrar un empleo e, incluso, a sentirse excluidos en ese mecanismo primordial que es el mercado de trabajo. La crisis de la década de los setenta del pasado siglo, la llamada Crisis del Petróleo, fue crucial en este sentido.

Las respuestas de los miembros de la segunda generación han sido muy variadas. Para algunos, la religión de sus padres ha sido un recurso autónomo, no controlado por la sociedad receptora, para encontrar la autoestima y, por lo mismo, la estima social. Nuevas funciones sociales se agregan a las que habitualmente consideramos como las estrictamente religiosas.

Cada sociedad de la vieja Europa occidental ha perdido aquella homogeneidad religiosa que le venía de Westfalia y aquella homogeneidad cultural que consiguió a través del proceso de construcción de su identidad nacional; $y$, además, la confesión religiosa que fue la religión de referencia en su territorio está comenzado a sufrir un proceso de minorización social. 
Religiones e identidades culturales y políticas diversas conviven, con mayor o menor fortuna, dentro de cada territorio llamado nacional.

Los procesos migratorios han traído consigo un nuevo desafío para las identidades nacionales que se configuraron a partir de una supuesta homogeneidad cultural y étnica. A ello se suma el empuje del proceso de globalización, no sólo económica, que ha puesto en jaque la prescripción propia del sistema de Estados-nación, según la cual debía existir un solapamiento entre un Estado, una cultura y un mercado integrado. En el caso de los paises europeos hay que añadir las consecuencias sociales de las políticas de austeridad dictadas en los últimos años desde ámbitos alejados de la soberanía nacional. Todo ello ha ocasionado un repunte de las identidades nacionales, como se aprecia, entre otros indicadores, en el ascenso de los partidos de extrema derecha. Se reclama una mayor soberanía económica, que puede llegar a traducirse en una salida de las instancias internacionales, como en el caso de Gran Bretaña con el Brexit. Estas instancias son percibidas por una parte de la población como demasiado lejanas, poco democráticas y causantes de una crisis económica y de unas políticas de ajuste que afectan de manera muy desigual a la city y a las clases populares, que en no pocas ocasiones giran su mirada hacia partidos políticos que reclaman mayores cuotas de soberanía nacional. En este contexto los inmigrantes y refugiados son vistos en ocasiones con un gran recelo, cuando no son tratados directamente con posturas racistas $y / 0$ xenófobas. Se les hace responsables de la bajada de salarios, de la pérdida de empleos, de aprovecharse de las prestaciones del Estado de Bienestar y de desafiar la cultura de las sociedades que les acogen. Ante ello se abren debates en torno a lo que caracteriza la identidad nacional y el modo de integrar a los inmigrantes. Debates que cuando se plasman en medidas concretas de indole jurídico-político muestran claramente el carácter imaginado de las comunidades nacionales (Anderson, 1993). Así se constata, por ejemplo, en el diseño de las preguntas de los test para conseguir la ciudadanía española por parte de los inmigrantes, test que difícilmente serían superados por una buena parte de la población autóctona y que dan cuenta de la enorme dificultad de establecer criterios claros y distintos que permitan delimitar la identidad nacional.

La convivencia con individuos procedentes de países que profesan diversas religiones reaviva uno de los temas fundamentales en los que convergen y entran en tensión la identidad nacional y la religiosa: la laicidad. ¿Qué lugar 
debe ocupar la religión en una sociedad democrática? ¿Debe quedar confinada al espacio privado, garantizándose su pleno ejercicio, o por el contrario puede, e incluso debe, tener presencia en el espacio público? Y en tal caso, ¿bajo qué presupuestos y condiciones? Son preguntas cuya recurrencia en la actualidad se ve acrecentada por diversos debates en torno a los símbolos religiosos en el espacio público, como, por ejemplo, el velo, el burka, el burkini, etc. Desde un punto de vista sociológico, queda todavía mucho que investigar en torno a lo que verdaderamente significa portar estas prendas. ¿Es señal de una identidad religiosa o esta se articula con otras sin poder ser claramente discernidas? En el caso de mujeres jóvenes que portan el velo en las sociedades occidentales, ¿es este un símbolo que refleja la dominación del patriarcado o, por el contrario, se convierte en un símbolo con otras connotaciones que se pueden articular incluso con identidades de género fruto de una distancia reflexiva con los roles tradicionales?

Ciertamente la religión ha jugado un papel central en la conformación de las identidades de género a lo largo de la historia. Y evidentemente lo sigue haciendo. En un contexto de creciente problematización de dichas identidades, algunos sectores religiosos se movilizan en contra de lo que llaman la ideología de género, a la que acusan de tener una mirada que desvirtúa la naturaleza de las cosas. Como decíamos anteriormente, en tanto que sociólogos, no nos compete juzgar la verdad de este tipo de posicionamiento, pero sí señalar que también se construye, como no podría ser de otro modo, a partir de una ideología que filtra la realidad a partir de la "naturaleza de las cosas". Ideología disfrazada desde la que se mantiene una postura firme y beligerante en contra del matrimonio entre personas del mismo sexo, tanto en España como en Francia, y que nos sitúa ante una cuestión social y sociológica de gran interés: ¿Cómo se articula la identidad de las personas homosexuales que han decidido contraer matrimonio con su identidad como católicos practicantes?

Algunos sectores de la iglesia católica, especialmente la jerarquía, toman partido en diversas materias bioéticas influyendo en la toma de decisiones políticas, como se aprecia en el caso de España. Atrás quedaron los años de nacional-catolicismo, uno de cuyos grandes objetivos fue la catolización de la vida de los españoles. Atrás quedó el monopolio del catolicismo sobre la religiosidad, abriéndose paso una nueva pluralidad religiosa, en la que la iglesia católica, aunque mayoritaria, ha de competir en el campo religioso con otras confesiones (Pérez-Agote y Santiago, 2009). Todavía quizás es 
demasiado pronto para poder hacernos una idea clara, pero parece que, frente a lo que sostiene la teoría de los "mercados religiosos", el aumento de la competitividad y de la oferta religiosa no se refleja en un incremento de la demanda. A la espera de poder contrastar esta hipótesis, nos parece más interesante constatar una de las dinámicas sociales que conlleva esta mayor competitividad en el campo religioso, que guarda relación con la etnicidad y el fenómeno migratorio. Nos referimos a la competencia entre las distintas confesiones religiosas por atraer nuevas poblaciones de inmigrantes, lo cual supone un fuerte desafío para la iglesia católica. Así se aprecia especialmente con respecto a la inmigración de América Latina, que, de tradición católica, ha empezado a engrosar de forma muy notable las filas del pentecostalismo. No obstante, este espectacular crecimiento no solo se da entre las poblaciones de inmigrantes, sino que también lo encontramos entre grupos étnicos autóctonos, como en el caso de los gitanos. ¿Cómo se articula en ellos la identidad étnica y la identidad religiosa?

Todas estas formas en las que se declina y adjetiva la identidad (individual, colectiva, nacional, étnica, de género) son objeto de estudio de este monográfico. La finalidad del mismo es volver sobre ellas analizando sus intersecciones con la religión, en un doble plano. Por un lado, con un carácter más analítico y teórico, sin el cual la sociología corre el riesgo de ser un discurso descriptivo. Por otro lado, con una exigencia más empírica, sin la cual la sociología corre el riesgo de convertirse en un discurso abstracto, sin anclajes con la realidad social. Con distintos grados y matices, los artículos que componen este monográfico tienen esta pretensión, la teorización y la construcción de un marco analítico deudores de la investigación empírica.

Ese es el caso del primer artículo, que firma Alfonso Pérez-Agote, que a la luz de una dilatada trayectoria de investigación empírica sobre temas de identidad colectiva y religión, nos propone una aproximación desde la teoría sociológica de la identidad a la religión con la que dar cuenta de las funciones sociales de esta. En su amplio recorrido, el artículo indaga en las estrechas relaciones entre las nociones de identidad y religión, analizando la identidad colectiva como una construcción social y la religión prestando atención al estatuto que puede alcanzar como dimensión límite, totalizadora de la identidad colectiva. Tras ello, Pérez-Agote nos sumerge a través de la sociología histórica en las consecuencias que ha tenido la globalización en las lógicas culturales de la modernidad y en el proceso de 
diferenciación de la religión, la política y la cultura. El trayecto concluye analizando, en el marco de la teoría de la diferenciación, la transformación de las relaciones entre estas tres esferas.

El artículo de Jose Santiago también propone un marco analítico y teórico con el que se examinan las complejas relaciones entre una de las formas en las que se declina la identidad colectiva, la identidad nacional, y la religión. Para ello se parte de una problematización de estas dos últimas categorías a la luz de una incursión por sus definiciones y rupturas epistemológicas. Para mostrar las potencialidades del marco analítico propuesto, se toman como referentes empíricos los casos de Quebec y el País Vasco. Desde una perspectiva comparada, Santiago analiza el papel desempeñado por la religión histórica o de sentido común como marcador que ha posibilitado el nacimiento de identidades nacionales. Retomando las rupturas epistemológicas de Durkheim y Hervieu-Léger, se muestra de qué modo la religión ha hecho plausible el mantenimiento de la identidad nacional, gracias a la conformación de un imaginario de continuidad mediante la sacralización de la historia y el territorio que lleva a cabo el nacionalismo.

Centrándose también en la intersección entre religión e identidad nacional, Juan Ignacio Castién nos traslada al Senegal contemporáneo para analizar la singular experiencia de construcción de una nación moderna en el mundo musulmán. Compaginando la sociología, la antropología y la historia, nos presenta una perspectiva general sobre las relaciones entre identidad nacional y religión en el mundo islámico, para posteriormente indagar en las especificidades del Islam senegalés a partir de su desarrollo histórico. El recorrido nos conduce por el período precolonial, el colonialismo y la independencia, mostrándonos las diversas y complejas vicisitudes históricas que permiten explicar lo que Castién califica como una experiencia exitosa, la de la conformación de una identidad nacional compatible con la democracia y la convivencia con la minoría cristiana. Frente a otras experiencias de corte fundamentalista, el caso de Senegal nos sitúa ante lo que el autor denomina como pragmatismo amable, una actitud vital más mundana y respetuosa con el otro.

Un estudio de caso es el que de igual modo nos ofrece Céline Béraud, en esta ocasión centrando su atención en Francia, en una temática en la que interseccionan la identidad religiosa y la identidad homosexual. Con el trasfondo de las movilizaciones contra la legalización del matrimonio y la adopción de parejas de personas con el mismo sexo, su artículo analiza el 
desafío que estas movilizaciones han supuesto para los católicos gays y lesbianas que tienen una fuerte integración en la iglesia. Gracias a una investigación cualitativa, Béraud se ha adentrado en el universo de los católicos practicantes que conviven con parejas del mismo sexo y que se han casado o tienen intención de hacerlo. El material obtenido permite analizar de qué modo cohabitan ambas dimensiones de identidad en un colectivo que ha sufrido tradicionalmente la condena de sus prácticas sexuales por parte del magisterio de la iglesia. Una identidad, tensionada, que ha conseguido un mayor reconocimiento, que se ha visto incluso reflejado en un acompañamiento a través de una ritualización de la unión de estas parejas por parte de un cura.

La polémica en torno al matrimonio homosexual, así como otros debates sobre diversas cuestiones de índole bioética o sobre la presencia de símbolos religiosos en el espacio público nos sitúan ante la laicidad y el encaje de las identidades religiosas en contextos democráticos. En este marco se encuadra el artículo de Mar Griera y Marian Burchard sobre el conflicto en torno a la regulación del velo integral islámico. A partir de un estudio de caso, su contribución analiza los procesos de problematización y regulación legal del velo integral a nivel local en Cataluña. El objetivo, en palabras de Griera y Burchard, es examinar las razones que explican la emergencia de esta problemática y analizar de qué manera se construyen los argumentos que apoyan o desaprueban la regulación local del uso del velo integral en el espacio público. La finalidad última es comprender cómo los discursos en torno a la laicidad y la religión en el espacio público se traducen en posiciones concretas, y cómo se configuran, articulan y confrontan diferentes concepciones sobre el significado, y los límites, de la libertad religiosa en el contexto de ese conflicto.

Por último, Antonio Montañés focaliza su atención en un colectivo en el que interseccionan la identidad religiosa y la identidad étnica, como es el que representan los gitanos pertenecientes al cristianismo carismático pentecostal. Tan es así que, según señala el autor, la extensión del pentecostalismo y los cultos entre los gitanos constituye uno de los fenómenos claves para entender la actual identidad y etnicidad gitana. Gracias a la realización de un trabajo de campo en la ciudad de Madrid, se analizan las recreaciones y articulaciones de la cultura e identidad gitana en dos iglesias cristiano-gitanas, como son la Iglesia Evangélica de Filadelfia y el Centro Cristiano Vino Nuevo el Rey Jesús, que luchan por alcanzar la hegemonía entre la población gitana. La tesis principal que 
defiende Montañés señala que ambas iglesias se han valido del cristianismo carismático pentecostal para autogestionar el cambio cultural en contextos de cambio social.

Este monográfico se cierra con la reseña de Joseba García Martín del libro Siete lecciones de sociología de la religión y del nacionalismo, de Jose Santiago, en el que se analiza, entre otros aspectos, la compleja y variada intersección entre religión e identidad nacional.

\section{BIBLIOGRAFİA}

Anderson, B. (1993). Comunidades imaginadas. Reflexiones sobre el origen y difusión del nacionalismo. México D.F.: Fondo de Cultura Económica.

Durkheim, E. (1968). Las formas elementales de la vida religiosa. Buenos Aires: Schapire.

Erikson, E. (1960). Enfance et société. Lausana: Delachaux et Niestlé.

Foucault, M. (1971). Nietzsche, la généalogie, l'histoire. In Hommage à Jean Hyppolite (pp. 145-172). París: Presses Universitaires de France,

Merton, R. K. (1980). Teoría y estructuras sociales. México D.F.: Fondo de Cultura Económica.

Pérez-Agote, A. (2008). Las raíces sociales del nacionalismo vasco. Madrid: Centro de Investigaciones Sociológicas.

Pérez-Agote, A., \& Santiago, J. (2009). La nueva pluralidad religiosa. Madrid: Ministerio de Justicia.

Simmel, G. (1896-97). Comment les formes sociales se maintiennent. L'Année Sociologique, 1, 71-109.

Tajfel, H. (1984). Grupos humanos y categorias sociales. Barcelona: Herder. 